\title{
Ensino de Geografia e Alterações Ambientais Globais na Educação Profissional e Tecnológica
}

\section{Geography Teaching And Global Environmental Changes In The Professional And Technological Education}

\author{
João Vitor Gobis Verges*a; Nivea Massaretto Verges ${ }^{\mathrm{b}}$

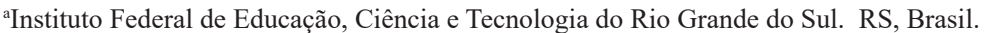 \\ 'Educação Básica. MT, Brasil. \\ *E-mail: vitorverges@gmail.com
}

\begin{abstract}
Resumo
As Alterações Ambientais Globais têm se colocado como pauta de inúmeras políticas e condicionantes culturais, econômicas e sociais em diferentes países no Mundo, sendo refletidas nas perspectivas educacionais. Dessa forma, procura-se, com este trabalho, apontar um cenário de concepção e de prática sobre as alterações ambientais globais no escopo do ensino de Geografia na educação profissional e tecnológica. Nesse sentido, o objetivo da pesquisa se assentou em desvelar os seguintes aspectos: 1) mecanismos metodológicos para as aulas desenvolvidas; 2) eixos analíticos sobre as Alterações Ambientais Globais; 3) instrumentos utilizados; 4) referenciais teóricos; 6) papel do livro didático; 7) enfoques formativos dos docentes. Para isto, foi aplicado um questionário a docentes de uma instituição da rede federal de educação profissional e tecnológica no Brasil, denominada Instituto Federal de Educação, Ciência e Tecnologia. O questionário foi empregado para 11 docentes, apresentando interrogações sobre os itens acima enumerados. Obteve-se como resultado que há o predomínio de aulas expositivas e seminários, as análises sobre o tema ocorrem, majoritariamente, pelas mudanças climáticas e desmatamento, as aulas se baseiam em maior parte nos documentários e gráficos, há a prevalência de referenciais teóricos brasileiros, ocorre a constatação ampla de que os livros didáticos são deficitários e mais de $35 \%$ dos professores consideram que suas formações não possuem enfoque para o trabalho com as Alterações Ambientais Globais.
\end{abstract}

Palavras-chave: Prática Docente. Meio Ambiente. Didática.

\begin{abstract}
Global Environmental Changes have been placed on the agenda of numerous policies, cultural, economic and social conditions in different countries in the world, being reflected in educational perspectives. Thus, this work seeks to point out a scenario of conception and practice on global environmental changes in the scope of teaching Geography in professional and technological education. In this sense, the objective of the research was based on unveiling the following aspects: 1) methodological mechanisms for the developed classes; 2) analytical axes on Global Environmental Changes; 3) instruments used; 4) theoretical references; 6) the textbook role; 7) teachers training approaches. For this, a questionnaire was applied to teachers of an institution of the federal network of professional and technological education in Brazil, called Federal Institute of Education, Science and Technology. The questionnaire was answered by 11 teachers, asking questions about the items listed above. It was obtained as a result that there is a predominance of expository classes and seminars, the analyzes on the subject are mainly due to climate change and deforestation, the classes are mostly based on documentaries and graphics, there is a prevalence of Brazilian theoretical references, it occurs the widespread finding that textbooks are deficient and more than $35 \%$ of teachers consider that their training does not have a focus on working with Global Environmental Changes.
\end{abstract}

Keywords: Teacher Practice. Environment. Didactic.

\section{Introdução}

A temática das Alterações Ambientais Globais tem recebido grande destaque no contexto de discussões políticas nacionais e internacionais, sobretudo em um momento em que se acirram problemas relacionados ao crescimento econômico dos países. Nesse sentido, é pertinente a identificação e discussão sobre como este recorte é tratado no processo de escolarização, especificamente, vinculado às dinâmicas do ensino.

Dessa forma, apresenta-se neste trabalho os resultados de uma pesquisa desenvolvida no segundo semestre de 2018 e primeiro semestre de 2019, procurando desvelar um cenário de atuação docente no escopo da disciplina de Geografia no contexto da Educação Profissional e Tecnológica.

Assim sendo, procurou-se levantar dados sobre como os docentes têm trabalhado as Alterações Ambientais Globais, em sala de aula, tomando por referência os seguintes aspectos: a) mecanismos metodológicos; b) eixos analíticos; c) instrumentos didáticos; d) referenciais teóricos; e) livros didáticos; f) aspectos formativos.

Os mecanismos metodológicos se atentam ao formato e encaminhamento das aulas; os eixos analíticos aos itens propostos para serem estudados como exemplares das Alterações Ambientais Globais; os instrumentos didáticos se referem aos materiais erguidos e mobilizados para as aulas; os referenciais teóricos correspondem aos fundamentos 
científicos para o trato com o tema; o livro didático é apreciado para a compreensão deste tradicional instrumento, no ambiente escolar, sobre o ensino e aprendizagem do recorte adotado; e os aspectos formativos evidenciam as possibilidades de diálogo com a temática, tendo em vista a trajet冈ria de construção intelectual dos professores.

Para a obtenção das informações foi aplicado um questionário para os docentes, sendo que as questões eram objetivas fechadas, com uma questão aberta para a indicação do referencial teórico utilizado. Os professores consultados pertenciam a um Instituto Federal de Educação, Ciência e Tecnologia da Rede Federal de Educação Profissional e Tecnológica no Brasil.

Com este movimento de pesquisa, foi possível tecer um quadro-parâmetro sobre como a abordagem relativa às Alterações Ambientais Globais vem sendo desenvolvida no ensino de Geografia, configurando uma faceta na realidade de execução do trabalho escolar com a questão indicada.

Por este caminho, o artigo irá expor o desenho metodológico para o desenvolvimento da pesquisa, realizar alguns apontamentos sobre a Rede Federal de Educação Profissional e Tecnológica no Brasil, apresentar os contornos gerais das Alterações Ambientais Globais e o ensino, os resultados obtidos com a aplicação dos questionários e uma discussão sobre as possibilidades e causas do cenário alcançado.

\section{Desenvolvimento}

\subsection{Metodologia}

Para o desenvolvimento da pesquisa foram utilizadas: a revisão bibliográfica sobre o Ensino de Geografia, Alterações Ambientais Globais e Educação Profissional e Tecnológica no Brasil - procurando contextualizar a problemática instaurada para investigação - e a obtenção de informações por meio de um questionário estruturado com perguntas fechadas e uma aberta.

O questionário foi aplicado para professores vinculados à Rede Profissional e Tecnológica do país, especificamente em um Instituto Federal de Educação, Ciência e Tecnologia, com perguntas sobre: a) mecanismos metodológicos que estão vinculados, majoritariamente, às abordagens no ensino sobre Alterações Ambientais Globais; b) os principais eixos analíticos sobre Alterações Ambientais Globais utilizados nas atividades de ensino; c) os instrumentos didáticos mobilizados para desenvolvimento das aulas sobre Alterações Ambientais Globais; d) referenciais teóricos angariados para fundamentar as Alterações Ambientais Globais no ensino; e) abordagens dos livros didáticos sobre as Alterações Ambientais Globais; f) aspectos formativos para trabalhar com a temática.

As perguntas fechadas do questionário apresentavam opções de respostas para os docentes, procurando traçar uma abordagem, em que as análises sistemáticas fossem possíveis. A pergunta aberta foi a que corresponde ao referencial teórico, permitindo aos professores a exposição de perspectivas que fundamentam os seus trabalhos.

Nesse sentido, as perguntas foram as seguintes:

1) Dos mecanismos metodológicos abaixo, qual está vinculado, majoritariamente, às suas abordagens no ensino sobre Alterações Ambientais Globais? Respostas possíveis: aulas expositivas, atividades dissertativas, projetos, seminários.

2) Quais os principais eixos analíticos sobre Alterações Ambientais Globais que você utiliza nas atividades de ensino? Respostas possíveis: mudanças climáticas, biodiversidade, desertificação, formação do Antropoceno, depósitos tecnogênicos, desmatamento, crise hídrica, desastres naturais.

3) Dos instrumentos apresentados a seguir, quais você, majoritariamente, utiliza para o desenvolvimento das aulas sobre Alterações Ambientais Globais? Respostas possíveis: documentários, artigos científicos, textos literários, maquetes, imagens de revistas, gráficos, material didático ilustrado, estudos de campo, textos de livros didáticos.

4) Poderia indicar dois referenciais teóricos que você utiliza para abordar as Alterações Ambientais Globais no ensino? Respostas abertas.

5) Os livros didáticos disponíveis em sua instituição abordam as Alterações Ambientais Globais de que forma? Respostas possíveis: excelente, mediana, fraca, inexpressiva.

6) Você possui enfoque formativo, pós-graduação Lato Sensu ou Stricto Sensu, voltado à compreensão das Alterações Ambientais Globais? Respostas possíveis: sim, não, enfoque parcial.

Para possibilidade de explanação geral e a realização de inferências não se nomeará, no artigo, a Unidade da Federação, os municípios e os campi em que os docentes participantes estavam vinculados. Com isso, é possível compreender os resultados encontrados como uma faceta de funcionamento da realidade docente em Geografia dos Institutos Federais.

\subsection{A Rede Federal de Educação Profissional e Tecnológica - os Institutos Federais}

A educação profissional e tecnológica no Brasil foi marcada por uma transformação no ano de 2008 com a criação dos chamados Institutos Federais de Educação, Ciência e Tecnologia (IF`s). O modelo de atuação desta instituição é inovador, pois não apresenta parâmetro similar em outros locais do Mundo (PACHECO, 2010), sendo caracterizado pela possibilidade de desenvolvimento dos estudos desde o Técnico Integrado ao Ensino Médio até o curso doutoral.

Para os Institutos Federais, tem-se a seguinte perspectiva:

[...] organização pedagógica verticalizada, da educação básica a superior, é um dos fundamentos dos Institutos Federais. Ela permite que os docentes atuem em diferentes níveis de ensino e que os discentes compartilhem os espaços de aprendizagem, incluindo os laboratórios, possibilitando o delineamento de trajetórias de formação que podem ir do curso técnico ao doutorado (PACHECO, 2010, p.13).

Assim, a docência nesta Instituição envolve uma ampla mobilização dos aparatos da didática, uma vez que se situa em diferentes momentos pedagógicos do processo de trabalho, o que, necessariamente, se apresenta como um desafio cotidiano para a atuação de professores. De forma análoga, Barbosa e Moura (2013) apontam o desafio da profissão docente 
na Educação Profissional e Tecnológica, indicando que é necessária a realização de inovações do leque de possibilidades didáticas com a utilização de novas dimensões metodológicas.

De maneira complementar, Pacheco (2010, p.14) expõe que, para os Institutos Federais:

[...] derrubar as barreiras entre o ensino técnico e o científico, articulando trabalho, ciência e cultura na perspectiva da emancipação humana, é um dos objetivos basilares dos Institutos. Sua orientação pedagógica deve recusar o conhecimento exclusivamente enciclopédico, assentandose no pensamento analítico, buscando uma formação profissional mais abrangente e flexível, com menos ênfase na formação para ofícios e mais na compreensão do mundo do trabalho e em uma participação qualitativamente superior neste. Um profissionalizar-se mais amplo, que abra infinitas possibilidades de reinventar-se no mundo e para o mundo, princípios estes válidos, inclusive, para as engenharias e licenciaturas.

É neste aspecto que reside a indagação sobre como os docentes vinculados a esta Rede trabalham com a temática das Alterações Ambientais Globais, uma vez que este tema é alvo de inúmeras indicações nos âmbitos de políticas, da economia e, também, das dimensões socioculturais.

Compreender a mobilização de recursos e a organização da docência, no que corresponde ao tema elencado permite discernir uma faceta sobre as possibilidades de construção de um futuro com cidadãos conscientes e compromissados com a condicionante ambiental.

\subsection{O ensino de Geografia e alterações ambientais globais: aspectos gerais}

Quando se relaciona o ensino da temática ambiental, nos espaços escolares, muitos desafios tendem a surgir. Como evidenciado por Jacobi et al (2011), as relações sobre o ambiente e o ensino costumam ocorrer com lacunas como: a) a competitividade econômica b) dist $\bigotimes$ ncias entre as políticas públicas ambientais e as escolas; c) falta de preparação suficiente dos professores; d) o enfoque cientificista e comportamentalista.

De acordo com Santos (2012), as Alterações Ambientais Globais se revestem de um caráter mais amplo e com múltiplas inter-relações dentro dos meandros ambientais. Por esta avaliação, é pertinente observar a conceituação, que traz sobre questão. Assim, tem-se que:

Alterações Globais em sentido lato são as mudanças que se dão à escala planetária na Terra e que resultam da evolução do sistema terrestre e das interacções e processos físicos, químicos e biológicos nos seus subsistemas, incluindo a litosfera, a hidrosfera, a cromosfera, a atmosfera e a biosfera (SANTOS, 2012, p.21).

Tavares (2010, p.14), tratando de um recorte específico nas alterações ambientais, aponta que para os estudantes: "[...] a escola tem contribuído pouco para que eles tenham um conhecimento fundamentado em argumentos científicos favoráveis ou desfavoráveis a essa perspectiva [...]", o que denota a contínua lacuna sobre as práticas e alicerces dos diferentes e inúmeros trabalhos executados.

Jacobi et al (2011) apresentam, ainda, que é comum encontrar o tratamento catastrofista e sensacionalista conjuntamente com a propagação de um cenário em que as pessoas tendem a se comportar de forma confusa, sem o discernimento de posicionamentos concretos (vide as perspectivas ligadas às mudanças climáticas).

Martinho e Talamoni (2007) destacam que, no trabalho da escola com as questões ambientais, é preciso levar em consideração que os estudantes carregam consigo uma série de saberes e informações que são do cotidiano. Ressaltam que é preciso uma aproximação com este conjunto de ideias, de valores e de condicionantes que demarcam o universo de inserção/percepção dos alunos no conjunto da temática ambiental em sala de aula (MARTINHO; TALAMONI, 2007).

Na perspectiva ambiental, Callai (1997) considera que as proposições trazidas já à época da inauguração dos Parâmetros Curriculares Nacionais (PCN) indicam a necessidade de se trabalhar superando as lógicas tradicionais. Enfatiza que:

Considerando-se que os problemas são sociais, a interpretação tem que ser social, compreendendo a história, e entendendoos como um processo. O espaço produzido pelos homens nesta trajetória, é o resultado dessa ação, e as formas de apropriação e uso da natureza resultam, acima de tudo, das relações sociais que se estabelecem, que são o mais das vezes conflituosas e contraditórias (CALLAI, 1997, p. 19).

Assim sendo, é assaz entender a questão das Alterações Ambientais Globais como um espaço, ainda, de amplo debate e necessidade de conhecimento, sobretudo, no escopo escolar. Uma vez que a temática envolve uma movimentação analítica entre a macroescala planetária e os seus subsistemas, é preciso levar em consideração (ou esperar) um conjunto didático promovido pelo docente capaz de dar vazão a um aprendizado significativo.

Por este aspecto, serão apresentados, no próximo tópico, os dados obtidos com a pesquisa realizada.

\subsection{Os Resultados da Pesquisa}

A partir da organização metodológica, que foi evidenciada, apresentam-se os resultados obtidos com o levantamento das informações através do questionário aplicado (Figuras 1 a 6).

Figura 1 - Dos mecanismos metodológicos utilizados pelos docentes.

Dos mecanismos metodológicos abaixo, qual está vinculado majoritariamente às suas abordagens no ensino sobre Alterações Ambientais Globais?

11 respostas

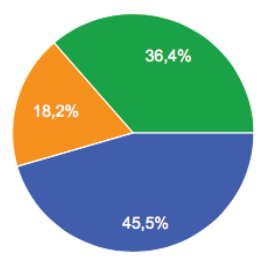

aula expositiva Atividades dissertativas Projetos - Seminários 
Figura 2 - Eixos analíticos utilizados pelos docentes.

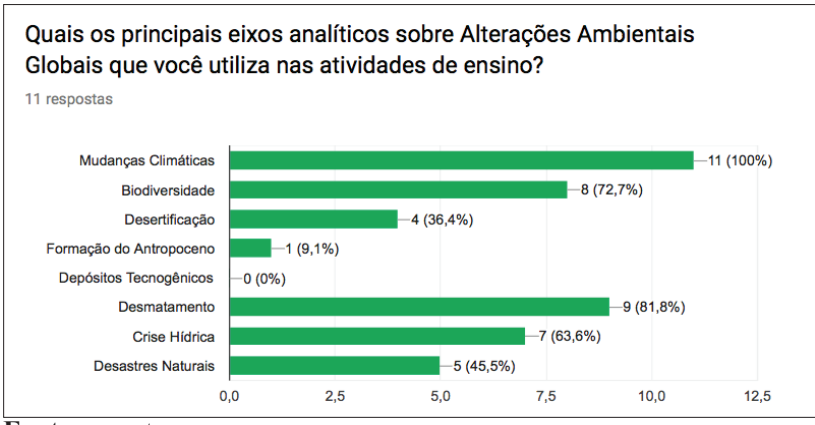

Fonte: os autores.

Figura 3 - Instrumentos utilizados para o desenvolvimento das aulas.

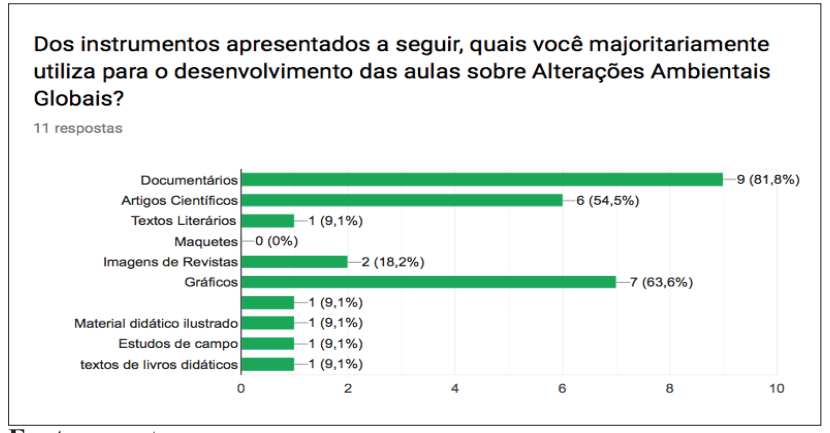

Fonte: os autores.

Figura 4 - Referenciais utilizados para abordar as Alterações Ambientais Globais.

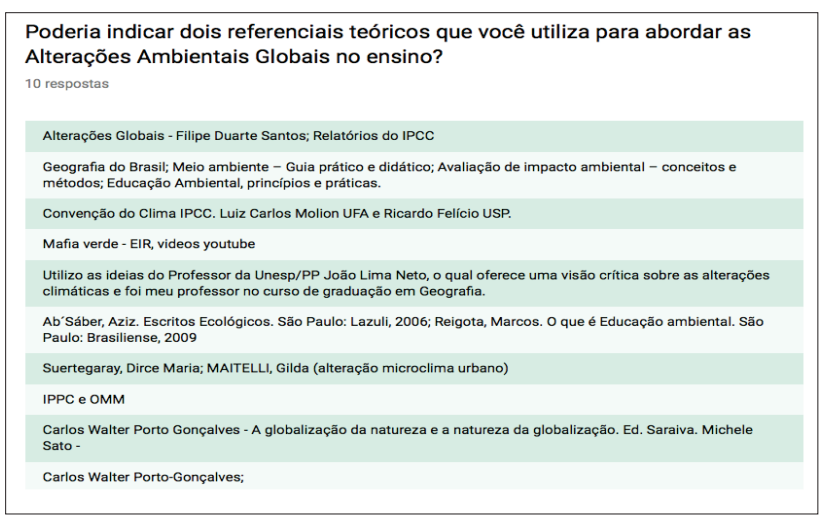

Fonte: os autores.

Figura 5 - Abordagem dos livros didáticos sobre as Alterações Ambientais Globais

Os livros didáticos disponíveis em sua instituição abordam as Alterações Ambientais Globais de forma:

11 respostas
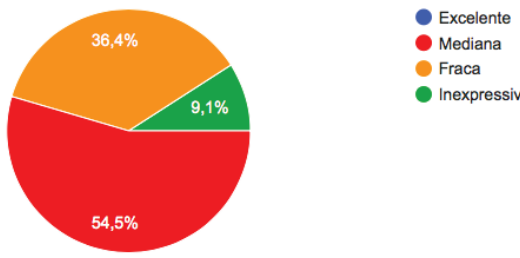

Inexpressiva
Figura 6 - Enfoque formativo sobre as Alterações Ambientais Globais.

Você possui enfoque formativo (pós-graduações Lato Sensu ou Stricto Sensu) voltado à compreensão das Alterações Ambientais Globais?

11 respostas

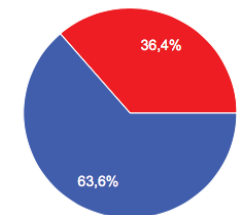

Sim

- Enfoque parcial - Abordagem tangencial do tema

Fonte: os autores.

Em síntese, é possível constatar que: a) os/as docentes utilizam, preponderantemente, as aulas expositivas e os seminários; b) os principais eixos analíticos foram as mudanças climáticas e o desmatamento; c) os materiais utilizados como base são maiormente os documentários e gráficos; d) nas referências teóricas predominam os materiais brasileiros; e) os livros didáticos são considerados, em maior parte, medianos ou fracos; f) mais de $35 \%$ dos professores consideram não possuir enfoque formativo para tratar das Alterações Ambientais Globais dentro de suas capacitações.

Tendo em vista os resultados alcançados, tem-se um quadro geral de um fragmento da Educação Profissional e Tecnológica que permite realizar inferências, ou seja, suporta a explanação sobre o que pode ser generalista dentro das atuações dos docentes em Geografia neste recorte adotado.

Por este aspecto, pontuar-se-ão as discussões sobre os dados levantados, de maneira que isso possa auxiliar na compreensão sequencial das verificações.

$\mathrm{Na}$ perspectiva dos mecanismos metodológicos, a maior concentração dos esforços docentes residiram nas aulas expositivas e nos seminários. Os projetos ficaram reduzidos a menos de $20 \%$ dos docentes consultados, já as atividades dissertativas dos estudantes não apareceram como caminho para o desenvolvimento do processo de ensino e aprendizagem na temática.

Isto pode indicar alguns entendimentos, sendo comum ocorrer a ação da "transferência bancária" do conhecimento, perspectiva paralela às evidenciadas em estudos de Freire (1997), Lins (2011) e Brighente (2016), assim como a recolha dos temas absorvidos pelos estudantes no formato de seminários, em que o professor avalia a informação e a apresentação.

Algumas verificações com relação aos seminários são encontradas na literatura sobre o tema, como a que se pode notar em Lima et al. (2009), em que se constata a atividade repartida entre os alunos, de modo que cada um procura e decora somente seu pedaço da apresentação, preocupando-se mais com a forma do que com as análises. Somando-se a isso, os demais estudantes não costumam fixar atenção nos grupos

Fonte: os autores.

1 Lins (2011, p.2), a partir dos estudos de Paulo Freire, evidencia educação bancária como: “[...] imposição do conhecimento realizada pelo professor sobre o aluno na medida em que o professor já os havia adquirido e dispõe destes, sendo assim possível sua ação de depósito deste conhecimento nos alunos". 
que se apresentam (LIMA et al, 2009).

Para os eixos analíticos, figuram como grandes elementos as mudanças climáticas e o desmatamento. Estes temas possuem elevada importância no processo de constatações sobre as alterações ambientais, todavia, demonstram que o alcance dos docentes pode ocorrer pelo viés imediato da abordagem, deixando de lado outras nuances, como solos, desastres naturais, formação do antropoceno etc. Há nesse encaminhamento a tendência da abordagem pela entrada e saída de gases com efeito estufa (GEE), alocando o tratamento generalista em uma perspectiva que envolve uma parte da questão (VERGES, 2015).

Alguns trabalhos apontam que, geralmente, as informações sobre os itens assinalados pelos docentes tendem a serem expressadas com certo sensacionalismo, vide Carneiro (2010), Jacobi et al (2011) e Teodoro e Amorim (2008), com forte presença dos meios jornalísticos/midiáticos. Outro fator que assente levar a reflexão indicada é o hiato de produções verificado sobre a amplitude da temática "Alterações Ambientais Globais", uma vez que mesmo os artigos científicos tendem a imprimir um recorte mais especificado sobre o assunto, como os direcionamentos para as mudanças climáticas.

Sobre os instrumentos mobilizados para a composição das aulas, os documentários e gráficos foram apontados como os mais utilizados para o desenvolvimento do processo pedagógico. Este levantamento acaba por se vincular ao relacionado aos eixos analíticos, uma vez que demonstram o caráter imediato/midiático e marcado pelos mecanismos mais pulverizados nos espaços de obtenção de informação, como os motores de busca na internet, sobretudo, no que corresponde às mudanças climáticas e ao desmatamento. Isto pode ser correlacionado, adicionalmente, à tendência de transferência de conhecimento por aulas expositivas.

$\mathrm{Na}$ perspectiva dos referenciais teóricos, o maior peso está nos materiais brasileiros. Somente um referencial de origem internacional foi apontando, somando-se aos organismos como o Intergovernmental Panel on Climate Change (IPCC) e Organização Meteorológica Mundial (OMM). Entre os fundamentos citados, houve destaque para ideias de professores sem a demonstração de obras e, também, vídeos do site Youtube.com. Esta perspectiva pode sinalizar dois aspectos iniciais, sendo um a dificuldade com línguas estrangeiras e outro a negação de autores que fogem dos escopos dos ambientes formativos da Geografia e Ciências Ambientais no país, além da busca rápida por materiais sintéticos em vídeos publicados na internet.

A utilização de livros didáticos foi demarcada como algo ruim, visto que a maioria dos professores relata que as obras são medianas ou fracas. Este fato suporta ser relacionado com a busca de encaminhamentos para as aulas em outros materiais de fácil acesso, o que corroboraria o amplo uso das vertentes midiáticas sobre desmatamento e mudanças climáticas.

Mais de 35\% dos docentes assinalaram não possuir enfoque formativo para trabalhar com as alterações ambientais globais. Nesse sentido, mesmo tendo cursado Geografia, com pós-graduação na área ou correlatas, e este tema sendo recorrente nas abordagens da disciplina no ensino da rede profissional e tecnológica, é necessário o contínuo processo de formação para os professores, tendo em vista os múltiplos desafios que se colocam para a docência.

Com isto, constrói-se uma tabela interpretativa (Quadro 1), relacionando os itens avaliados com as indicações gerais apontadas pelos professores consultados e possíveis causas para o desembocar nos dados encontrados. Assim, generalizam-se os itens levantados com os dados gerais obtidos pelas repostadas dos professores, apresentando causas possíveis.

Quadro 2 - Relação entre os dados encontrados e suas possíveis causas - Ensino de Geografia e Alterações Ambientais Globais na Educação Profissional e Tecnológica

\begin{tabular}{|c|c|c|}
\hline $\begin{array}{c}\text { Itens } \\
\text { Levantados }\end{array}$ & $\begin{array}{l}\text { Dados Gerais } \\
\text { Obtidos por } \\
\text { respostas dos } \\
\text { professores }\end{array}$ & Causas Possíveis \\
\hline $\begin{array}{l}\text { Mecanismos } \\
\text { Metodológicos }\end{array}$ & Educação bancária & $\begin{array}{l}\text { Projeto Pedagógico dos } \\
\text { cursos / inclinações } \\
\text { profissionais do/a } \\
\text { docente }\end{array}$ \\
\hline $\begin{array}{l}\text { Eixos } \\
\text { Analíticos }\end{array}$ & $\begin{array}{l}\text { Caráter midiático } \\
\text { - Temas mais } \\
\text { propagados }\end{array}$ & $\begin{array}{l}\text { Facilidade na obtenção } \\
\text { de dados / Carência no } \\
\text { viés formativo }\end{array}$ \\
\hline $\begin{array}{l}\text { Instrumentos } \\
\text { Utilizados }\end{array}$ & Caráter midiático & $\begin{array}{l}\text { Facilidade na obtenção } \\
\text { de dados / Carência no } \\
\text { viés formativo }\end{array}$ \\
\hline $\begin{array}{l}\text { Referenciais } \\
\text { Teóricos }\end{array}$ & $\begin{array}{l}\text { Majoritariamente } \\
\text { brasileiros }\end{array}$ & $\begin{array}{l}\text { Não aceitação de } \\
\text { referências internacionais } \\
\text { / dificuldade com outras } \\
\text { línguas } \\
\end{array}$ \\
\hline $\begin{array}{l}\text { Livros } \\
\text { Didáticos }\end{array}$ & $\begin{array}{l}\text { Considerados } \\
\text { inadequados }\end{array}$ & $\begin{array}{l}\text { Não aceitação de } \\
\text { autores, referências ou } \\
\text { abordagens }\end{array}$ \\
\hline $\begin{array}{l}\text { Enfoques } \\
\text { Formativos }\end{array}$ & $\begin{array}{l}\text { Mais de } 1 / 3 \text { indica } \\
\text { não possuir }\end{array}$ & $\begin{array}{l}\text { Falta de capacitação } \\
\text { contínua }\end{array}$ \\
\hline
\end{tabular}

Fonte: Dados da pesquisa.

Assim, é plausível indicar que as abordagens sobre o ensino das Alterações Ambientais Globais no escopo da Geografia na Educação Profissional e Tecnológica, observando o grupo estudado, não ultrapassam os encaminhamentos criticados por diferentes estudos educacionais ${ }^{1}$.

$\mathrm{O}$ processo de instrução se alinhavou à tendência de apresentação dos conteúdos, a partir de uma autoridade que ensina, o professor ou um seminário, o caráter midiático é relevante nos instrumentos utilizados e nas formas de conceber a aula, o ponto de partida é, majoritariamente, nacional e com enfoques para ambientes midiáticos como o Youtube. com, além de parcela significativa dos docentes informar não 
possuírem capacitação específica para trabalharem com o tema.

\section{Conclusão}

Procurou-se evidenciar e analisar os resultados obtidos com uma pesquisa junto aos docentes de Geografia da Educação Profissional e Tecnológica, observando o recorte do ensino das Alterações Ambientais Globais.

É possível compreender que existem inúmeros desafios para o aprimoramento da didática no desenvolvimento dos componentes pedagógicos, que compõem as ações na temática, procurando ampliar as possibilidades formativas para a existência de cidadãos compromissados com as interações positivas entre as sociedades e a natureza.

De forma geral, indica-se a ampliação dos estudos através das análises sobre os mecanismos midiáticos, que influenciam os docentes e os fundamentos que abordam os livros didáticos, tendo em vista que estes dois itens foram expressivos dentro dos alcances desta pesquisa.

\section{Referências}

TEODORO, P.H.M.; AMORIM, M.C.C.T. Mudanças climáticas: algumas reflexões. Rev Bras. Climatol., v. 3, 2008. doi: http:// dx.doi.org/10.5380/abclima.v3i0.25405

CARNEIRO, C.M.Z. Narrativa sensacionalista e ficção especulativa sobre o aquecimento global: catarse, alerta, realidade e ficção em" O Dia Depois de Amanhã". C-Legenda, n. 22, 2010.

FREIRE, P. Educação "bancária" e educação libertadora. Introd. Psicol. Esc., v.3, p.61-78, 1997.

SAVIANI, D. A pedagogia histórico-crítica e a educação escolar. Pensando Educ., p.23-33, 1989.
LIBANEO, J.C. Tendências pedagógicas na prática escolar. $A N D E$, v.3, p.11-19, 1983.

ALVES, M.A.; GHIGGI, G. Levinas e a educação: da pedagogia do Mesmo à pedagogia da Alteridade. Rev. Sul-Am. Filos. Educ., v.15, p.95-111, 2010.

BRIGHENTE, M.F. Paulo Freire: da denúncia da educação bancária ao anúncio de uma pedagogia libertadora. Pro-Posições, v.27, n.1, p.155-177, 2016.

LIMA, P.B. et al. Aulas teóricas x apresentação de seminários: vantagens e desvantagens. In: JORNADA DE ENSINO, PESQUISA E EXTENSÃO, 2009, RECIFE. ANAIS DO IX JORNADA DE ENSINO, PESQUISA E EXTENSÃO. 2009. Recife: Imprensa Universitária da UFRPE, 2009. v. 1. p. 1-3.

PACHECO, E.M. Os Institutos Federais: uma revolução na educação profissional e tecnológica. Natal: IFRN, 2010.

JACOBI, P.R. et al. Mudanças climáticas globais: a resposta da educação. Rev. Bras. Educ., v.16, n.46, 2011.

TAVARES, A.C. et al. Aquecimento global e mudanças climáticas na visão de estudantes do ensino médio. CLIMEP, v.5, n.1, 2010.

BARBOSA, E.F.; DE MOURA, D.G. Metodologias ativas de aprendizagem na educação profissional e tecnológica. Bol. Técnico Senac, v.39, n.2, p.48-67, 2013.

CALLAI, H.C. O meio ambiente no ensino fundamental. Terra Livre, n. 13, p.9-19, 1997.

LINS, M.J.S.C. Educação bancária: uma questão filosófica de aprendizagem. Rev. Educ. Cultura Contemp., v.8, n.16, 2011.

VERGES, J.V.G. Ensino de Geografia e mudanças climáticas: análise sobre a coleção "explorando o ensino"-MEC (20042010). Rev. GeoUECE, v.4, n.6, p.81-107, 2015.

MARTINHO, L.R.; TALAMONI, J.L.B. Representações sobre meio ambiente de alunos da quarta série do ensino fundamental. Ciênc. Educ., v.13, n.1, p.1-13, 2007. 